\title{
Characterization of Post-Rainy Season Grown Indigenous and Exotic Germplasm Lines of Sorghum for Morphological and Yield Traits
}

\author{
Ashok Badigannavar ${ }^{1}$, A. Ashok Kumar ${ }^{2}$, G. Girish ${ }^{3}$, T.R. Ganapathi ${ }^{1}$ \\ ${ }^{1}$ Nuclear Agriculture and Biotechnology Division Bhabha Atomic Research Centre Trombay, Mumbai 400085, India \\ ${ }^{2}$ International Crops Research Institute for the Semi-Arid Tropics (ICRISAT), Hyderabad 502324, India \\ ${ }^{3}$ Agricultural Research Station, Aland road, Gulbarga 585101, India
}

\begin{abstract}
Sorghum is a major staple crop and vital for the marginal farmers in Asian and African countries. Landraces or germplasm lines adapted to biotic and abiotic stresses are the prime source of adaptive traits in the crop breeding programs. In order to assess the genetic variability, 141 exotic germplasm lines and 36 popular varieties were evaluated for eight agro-morphological traits. Wide range of values were observed for grain yield (6.6-124.4 g/plant), seed index (1.5-7.1 g/100 seeds), panicle length (8-44 cm) and panicle width $(7.25 \mathrm{~cm})$. High genotypic and phenotypic coefficient of variation was observed for grain yield per plant. The values of broad sense heritability in the sorghum core population ranged from 0.75 to 0.99 . Seed weight, days to flowering, panicle width and leaf area were significantly correlated with grain yield $(P \leq 0.01)$. Seed weight was positively correlated with panicle width (correlation coefficient 0.31 ), while negatively correlated with panicle length (correlation coefficient -0.15 ). Cluster analysis resolved all the genotypes into four major clusters. Among germplasm lines, TSG-313 had high seed weight of $7.05 \mathrm{~g} / 100$ seeds, while TSG-325 had highest grain yield of $124.4 \mathrm{~g} /$ plant as against control variety. Germplasm lines with high heritability scores would help us to utilise them in recombination breeding.
\end{abstract}

Keywords Genetic diversity, Sorghum germplasm, Correlation, Cluster analysis

\section{INTRODUCTION}

Sorghum is a staple crop cultivated in the semi-arid and sub-tropical regions of Africa and Asian countries. It is one of the most drought-tolerant cereal crops, which is cultivated for food, feed, fiber, and fuel. Globally sorghum covered an area of 44.96 mha with grain production of 68.93 million tonnes and Asian countries contributed to an extent of $19.6 \%$ of the global production (FAO 2014). In India, sorghum is grown on 6.18 mha contributing $14.63 \%$ of the global area with a production estimate of 5.28 million tonnes (Charyulu et al. 2013). Sorghum adapts to many environments, requiring 90 to 140 days to mature. Culti- vated in diverse climates and environmental conditions, the challenges of increasing productivity on marginal lands and cooler climates remain at the forefront of sorghum improvement efforts worldwide (Burow et al. 2011).

There are five cultivated races in sorghum, viz., bicolor, kafir, durra, caudatum and guinea. It is suggested that sorghum is domesticated and originated in North-East quadrant of Africa, most likely in the Ethiopian-Sudan border (Doggett 1988). In order to harness wide variability, utilisation of germplasm lines in the breeding programs would be the good option. Core and mini-core collections have been developed in many crops including sorghum (Upadhyaya et al. 2009) and they are useful in finding

Received April 17, 2017; Revised May 12, 2017; Accepted May 14, 2017; Published June 1, 2017

*Corresponding author Ashok Badigannavar, ashokmb1@gmail.com, Tel: +91-22-25592335, Fax: +91-22-25505151 
germplasm lines with agronomically beneficial traits, such as resistance to abiotic/biotic stresses and seed quality parameters.

Studies on phenotypic and genetic diversity are essential to identify groups with similar genetic backgrounds for conserving, evaluating and utilizing genetic resources of pre-breeding and breeding germplasm (Franco et al. 2001) Indian sorghum landraces possess moderate to high genetic variability, but their utilization in breeding programs for improving yield and seed quality has not been realized (Reddy et al. 2012). Assessment of genetic variability has accordingly become an essential component in identifying potential parents for recombination breeding. It is also essential to study the association of yield components with yield under varied agro-climatic conditions. Attempts have been made in the past to estimate the extent of genetic variability among the accessions from Ethiopia (Mamo et al. 2007), North Shewa and Douth Welo (Teshome et al. 1997) and India (Seetharam and Ganeshmurthy 2013). Most of these studies were done with limited number of local genotypes grown in single or multiple environments. Both grain number and grain yield are quantitative traits governed by polygenes and have low heritability and high genotype and environmental interaction, which complicate selection strategies for these traits in breeding programs (Chapman et al. 2000). The identification of secondary traits that have an impact on grain number and yield, showing diversity across genotypes and less environmental variation, becomes a best approach for yield improvement (Araus et al. 2008).

Efficient utilisation of the genetic potential held in germplasm collections requires detailed knowledge about the collections (Beuselinck and Steiner 1992), including characterisation, evaluation and classification. However, it is difficult to categorise the variation in germplasm collections for economic purposes (Prasad et al. 1989). Multivariate methods are useful for characterisation, evaluation and classification of plant genetic resources when a large number of accessions are to be assessed for several characters of agronomic and physiological importance (Peeters and Martinelli 1989). In this context, present study focus on a fair collection of Indian post rainy season grown sorghum landraces along with representative germplasm lines from five races were evaluated. This study will also assess morphological variations among the sorghum landraces and varieties, estimate genetic parameters and classify the genotypes based on genetic similarity using cluster analysis.

\section{MATERIALS AND METHODS}

\section{Experimental materials and data collection}

The material used in this study comprised of 141 germplasm lines and 36 varieties including popular variety M-35-1, which were collected from ICRISAT and NBPGR, Hyderabad (Supplementary Table S1). Most of the local landraces and varieties are adapted to Central and South Indian states, while germplasm lines are adapted to Asian and African countries. The cultivation of these landraces was mainly in post-rainy season on a shallow to deep black soil. These genotypes were grown in two replications following Incomplete Block Design at Agricultural Research Station, Gulbarga, Karnataka during post rainy season of 2013-2014. The climatic conditions of the experimental site were characterized by a limited amount of rainfall and high temperatures during the crop growth. The experiment was laid out in two rows of $5 \mathrm{~m}$ length with $45 \times 15 \mathrm{~cm}$ spacing. All the agronomic practices were followed to raise the ideal and healthy crop. Seven quantitative characters viz., plant height $(\mathrm{cm})$, days to flower, panicle length and width $(\mathrm{cm})$, grain yield per plant $(\mathrm{g}), 100$ seed weight $(\mathrm{g})$, total chlorophyll content and leaf area were recorded on five randomly selected plants as per the standard descriptors. Briefly, plant height was determined as the length of the plant between the base and the tip of the panicle. Panicle area was calculated by measuring length and width of each panicle. Plant yield was measured as the weight of the seed threshed from individual panicles. Seed index was recorded as the weight of one hundred grains from bulk seeds from each head of the genotypes grown. The fully opened leaf were selected at the time of flowering and from 10 randomly selected plants of each genotype total chlorophyll content and leaf area was measured using the chlorophyll meter (SPAD-502 Minolta, Japan). 


\section{Statistical analyses}

In the present study, data were recorded from five plants in each replication and averaged. The data were subjected to analysis of variance for each environment and for the combined data using PROC GLM of SAS 9.1 (SAS 2010). Genetic parameters were estimated to identify genetic variability among accessions and determine genetic and environmental effects on different traits. Genotypic $\left(\sigma_{G}^{2}\right)$, phenotypic $\left(\sigma_{\mathrm{P}}^{2}\right)$ and error $\left(\sigma_{\mathrm{E}}^{2}\right)$ variances were calculated for each trait from the pooled ANOVA table. Phenotypic coefficient of variation (PCV) and genotypic coefficient of variation $(\mathrm{GCV})$ were calculated as per the standard formula (Burton 1952). The extent of variation among the genotypes was estimated as broad sense heritability and defined as the ratio of the genetic variance $\left(\sigma_{\mathrm{G}}^{2}\right)$ between genotypes to the total phenotypic variance $\left(\sigma_{\mathrm{P}}^{2}=\sigma_{{ }_{\mathrm{G}}}{ }+\sigma_{\mathrm{E}}^{2}\right)$ (Allard 1960). In order to determine genetic relationship among the different variables, Pearson correlation coefficients were calculated for every pair of traits using the PROC CORR of SAS procedure. A cluster analysis of the morphological data was performed using Euclidean distances and dendrogram was constructed.

\section{RESULTS}

\section{ANOVA and univariate analysis}

The analysis of variance indicated significant variation among the genotypes for all the traits except chlorophyll content and leaf area (Table 1). Coefficient of variation ranged from $18.76 \%$ (grain yield/plant) to $3.69 \%$ (plant height). The mean, range and genetic parameters for different morphological traits measured in 177 sorghum genotypes are presented in Table 2. Among the traits studied, plant height, grain yield, seed weight, panicle length and width showed wide range of values. The increased grain yield $(6.6-95.1 \mathrm{~g} / \mathrm{plant})$ was due to the

Table 1. Analysis of variance for yield traits in sorghum genotypes.

\begin{tabular}{lrcccccccc}
\hline \hline \multirow{2}{*}{ Source } & \multirow{2}{*}{ df } & \multicolumn{7}{c}{ Mean squares ${ }^{\text {z) }}$} \\
\cline { 3 - 9 } & & Yld & SW & Ht & Flr & PL & PW & Chl & LA \\
\hline Genotypes & 175 & $471.08^{* *}$ & $0.86^{* *}$ & $4,292.36^{* *}$ & $102.53^{* *}$ & $65.69^{* *}$ & $4.99^{* *}$ & 36.15 & 0.0009 \\
Rep. & 1 & 354.20 & $0.27^{* *}$ & $599.30^{* *}$ & 1.76 & 6.42 & 3.64 & 29.56 & 0.00001 \\
Error & 177 & 115.66 & 0.04 & 39.75 & 5.85 & 6.48 & 2.05 & 35.27 & 0.00008 \\
CV (\%) & & 18.76 & 5.82 & 3.69 & 4.33 & 7.26 & 11.06 & 11.27 & 18.38 \\
\hline
\end{tabular}

*Significant at the 0.05 probability level, **Significant at the 0.01 probability level, CV: Co-efficient of variation. ${ }^{2)}$ Yld: Grain yield/plant $(\mathrm{g})$, SW: Seed weight $(\mathrm{g})$, Ht: Plant height $(\mathrm{cm})$, Flr: Days to flower, PL: Panicle length $(\mathrm{cm})$, PW: Panicle width $(\mathrm{cm})$, Chl: Chlorophyll content, LA: Leaf area.

Table 2. Comparison of sorghum germplasm lines and varieties for yield contributing traits ${ }^{2)}$.

\begin{tabular}{ccccccccc}
\hline \hline & Yld & SW & Ht & Flr & PL & PW & Chl & LA \\
\hline Germplasm & & & & & & & & \\
$\quad$ Numbers & 141 & 141 & 141 & 141 & 141 & 141 & 141 & 141 \\
Mean & 29.75 & 3.26 & 168.04 & 55.64 & 19.36 & 4.43 & 52.68 & 0.023 \\
Range & $6.7-66.15$ & $1.75-7.05$ & $37.97-263.37$ & $35-73.5$ & $9-33.5$ & $2.0-8.5$ & $37.05-60.90$ & $0.007-0.04$ \\
Varieties & & & & & & & & \\
$\quad$ Numbers & 36 & 36 & 36 & 36 & 36 & 36 & 36 & 36 \\
Mean & 39.91 & 3.35 & 181.91 & 56.72 & 20.45 & 5.29 & 52.78 & 0.02 \\
Range & $7.55-95.1$ & $2.55-4.05$ & $100.45-251.13$ & $48.5-64.5$ & $10.5-31.5$ & $2.5-14.5$ & $41.95-63.2$ & $0.011-0.034$ \\
\hline
\end{tabular}

${ }^{\text {z) } Y l d: ~ G r a i n ~ y i e l d / p l a n t ~}(\mathrm{~g})$, SW: Seed weight $(\mathrm{g})$, Ht: Plant height $(\mathrm{cm})$, Flr: Days to flower, PL: Panicle length $(\mathrm{cm})$, PW: Panicle width (cm), Chl: Chlorophyll content, LA: Leaf area. 
increased seed weight (1.5-7.1 g/100 seeds), panicle length $(8-44 \mathrm{~cm})$ and panicle width $(7-25 \mathrm{~cm})$. Physiological traits such as chlorophyll content and leaf area also recorded wide range values of 25.5-67.4 and 0.0018-0.05 respectively. From the present study, one of the promising varieties, ICSV-13001 showed high grain yield (95.10 $\mathrm{g} / \mathrm{plant})$ contributed by the high seed index $(3.9 \mathrm{~g} / 100$ seeds) and long panicle $(21 \mathrm{~cm})$, but flowered in 63 days. Among the germplasm lines, IC436598 showed high grain yield $(73.3 \mathrm{~g} /$ plant $)$ due to increased panicle length $(24 \mathrm{~cm})$ and width $(6.5 \mathrm{~cm})$.

\section{Estimation of genetic parameters}

High genotypic and phenotypic coefficient of variation was observed for grain yield per plant (59.24 and 68.20\% respectively), while the lowest value was recorded in leaf area (0.97 and $4.01 \%$ respectively) (Table 3 ). GCV and
PCV values for yield contributing traits were relatively higher as compared to highly variable morphological traits, viz., days to flower, plant height and leaf area. The values of broad sense heritability in the sorghum population ranged from 0.75 to 0.99 . Broad sense heritability was higher panicle length, width plant height, chlorophyll content and leaf area $(>0.99)$ as compared to grain yield and seed weight $(>0.75)$. Genetic advance varied from $0.02 \%$ (leaf area) to $132.21 \%$ (plant height).

\section{Genetic comelation and cluster analysis}

Correlation coefficients between eight morphological and yield traits are presented in Table 4. Seed weight, days to flowering, panicle width and leaf area were significantly correlated with grain yield $(P \leq 0.01)$. Among the other correlations, seed weight was positively correlated with panicle width (correlation coefficient $0.31^{* *}$ ), while

Table 3. Genetic parameters ${ }^{\mathrm{z})}$ for grain yield and contributing traits in sorghum germplasm lines.

\begin{tabular}{lccccrrr}
\hline \multicolumn{1}{c}{ Traits } & Mean & \multicolumn{1}{c}{$\mathrm{Vg}$} & \multicolumn{1}{c}{$\mathrm{Vp}$} & $\mathrm{GCV}$ & $\mathrm{PCV}$ & $\mathrm{H}^{2}$ & $\mathrm{GA}$ \\
\hline Yield/plant (g) & 31.82 & 355.42 & 471.08 & 59.24 & 68.20 & 0.75 & 33.66 \\
seed weight (g) & 3.28 & 0.828 & 0.86 & 27.74 & 28.27 & 0.76 & 1.44 \\
Days to flower & 55.86 & 96.68 & 102.53 & 17.60 & 18.12 & 0.96 & 20.06 \\
Panicle length (cm) & 19.58 & 59.20 & 65.69 & 39.29 & 41.39 & 0.98 & 16.32 \\
Panicle width (cm) & 4.61 & 2.94 & 4.99 & 37.19 & 48.45 & 0.98 & 4.52 \\
Plant height (cm) & 170.86 & $4,252.61$ & $4,292.36$ & 38.16 & 38.34 & 0.98 & 132.21 \\
Chlorophyll content & 52.7 & 0.88 & 36.15 & 1.78 & 11.40 & 0.99 & 12.34 \\
Leaf area & 0.23 & 0.000005 & 0.000085 & 0.97 & 4.01 & 0.99 & 0.02 \\
\hline
\end{tabular}

${ }^{\mathrm{z})} \mathrm{Vg}$ and $\mathrm{Vp}$ : Genetic and phenotypic variances, GCV and PCV (\%): Genetic and phenotypic coefficient of variation, $\mathrm{H}^{2}$ : Broad sense heritability, GA: Genetic advance.

Table 4. Correlation coefficients for grain yield and contributing traits ${ }^{\mathrm{z})}$ in sorghum germplasm lines.

\begin{tabular}{llllllll}
\hline \hline Trait & Yld & SW & Ht & Flr & PL & PW & Chl \\
\hline Yield & 1 & & & & & \\
SW & $0.31^{* *}$ & 1 & & & & \\
Ht & $0.11^{*}$ & 0.06 & 1 & & & & \\
Flr & $0.23^{* *}$ & -0.03 & $0.42^{* *}$ & 1 & & & \\
PL & $0.13^{*}$ & $-0.15^{* *}$ & $0.11^{*}$ & 0.05 & 1 & & 1 \\
PW & $0.38^{* *}$ & $0.31^{* *}$ & $0.28^{* *}$ & $0.24^{* *}$ & 0.08 & & \\
Chl & 0.006 & 0.04 & 0.07 & 0.02 & 0.01 & 0.05 & 1 \\
LA & $0.29^{* *}$ & $0.14^{* *}$ & $0.12^{*}$ & $0.31^{* *}$ & -0.06 & $0.20^{* *}$ & $0.11^{*}$ \\
\hline
\end{tabular}

*Significant at the 0.05 probability level, **Significant at the 0.01 probability level.

${ }^{\mathrm{z})}$ Yld: Grain yield/plant (g), SW: Seed weight (g), Ht: Plant height $(\mathrm{cm})$, Flr: Days to flower, PL: Panicle length (cm), PW: Panicle width $(\mathrm{cm})$, Chl: Chlorophyll content, LA: Leaf area. 


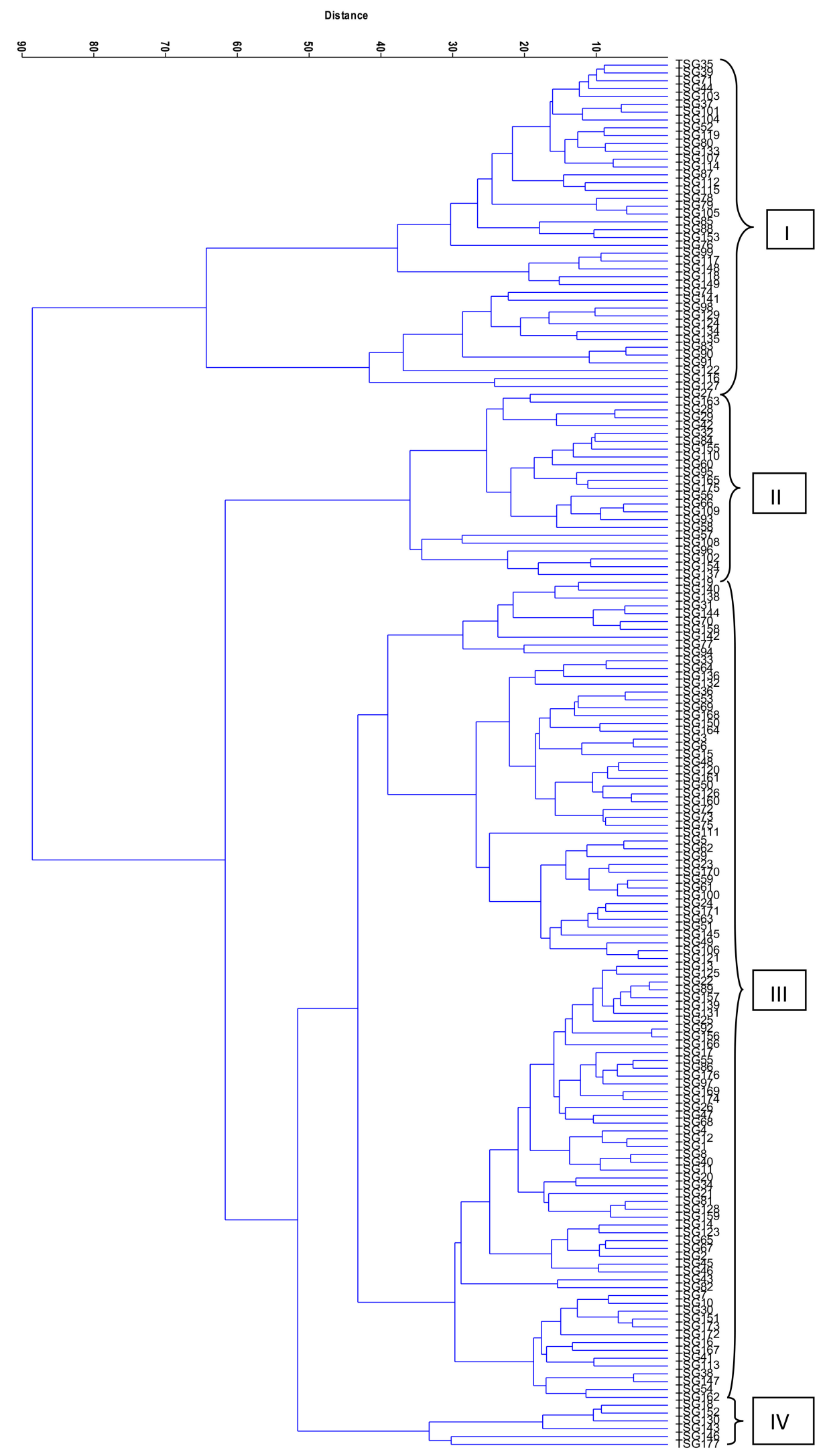

Fig. 1. Cluster analysis among the sorghum genotypes based on Euclidean distances. 
negatively correlated with panicle length $\left(-0.15^{* *}\right)$. Leaf area was positively correlated with grain yield $(0.29 * *)$, seed weight $\left(0.14^{* *}\right)$, plant height $\left(0.12^{*}\right)$, days to flower $\left(0.31^{* *}\right)$, panicle width $\left(0.20^{* *}\right)$ and chlorophyll content $(0.11 *)$.

The morphological data were used to calculate Euclidean distances between sorghum genotypes and a dendrogram was constructed (Fig. 1). Cluster analysis resolved all the genotypes into four major clusters. Clusters I and II had 42 and 24 genotypes, while III and IV had 105 and 6 genotypes respectively. Distribution, mean and range values for each cluster are shown in the Table 5. Based on the mean and range values, cluster IV showed highest mean grain yield (73.07 g/plant) with wide range values (62.15-95.10 $\mathrm{g} /$ plant) as compared to other genotypes. The high yield was contributed by the high mean panicle length (21.13 $\mathrm{cm})$ and width $(5.88 \mathrm{~cm})$. ICSV-13001 and DSV-4 were found to be high yield against rest of the genotypes with a mean grain yield of 95.10 and $85.35 \mathrm{~g} /$ plant respectively. Most of the early flowering genotypes were grouped in cluster I (51 days). Tall plants and bold seeded genotypes were grouped in cluster II and III with a mean value of $236.02 \mathrm{~cm}$ and $3.35 \mathrm{~g} / 100$ seeds respectively. Extra bold seeded genotype, TSG-313 showed 100 seed weight of $7.05 \mathrm{~g}$ as against control, DSV-4 possessing $3.35 \mathrm{~g}$. Across the genotypes studied, mean values for these two parameters did not show any significant difference. High yielding genotypes with wide range values were grouped in the cluster IV. ICSV 13001 and DSV-4, popular released varieties had high grain yield per plant. TSG-467 was extra early, flowered in 37 days, while TSG-313 showed extra bold seed ( $7.05 \mathrm{~g} / 100$ seeds).

\section{DISCUSSION}

Landraces are the reservoir of genetic variability in most of the field crops. Although spread of research varieties is being used repeatedly in the cross breeding programs leading to narrowing of gene pool (Elangovan et al. 2012). Hence collection of diverse germplasm lines (landraces or improved cultigens) from different agroclimatic conditions would help in broadening of the genetic base. M-35-1, a selection from landrace has been traditionally grown by the farmers since several decades and released as variety and dominates the post rainy season sorghum area in India. There is need to develop high yielding, dual purpose sorghum varieties with superior seed quality traits in replacement of the M-35-1. In this context, the present study was undertaken to characterize landraces, improved cultivars and released varieties for morpho-physiological and grain yield contributing traits.

From the present study, it was evident that wide range values were observed for grain yield, seed weight, panicle area and physiological traits like leaf area and chlorophyll content. Previous studies have also shown significant pooled deviation for grain and fodder yield indicating varietal difference for yield parameters (Narkhede et al. 1997; Patil et al. 2007; Prabhakar et al. 2010). Among the 34 sorghum landraces from Ethiopea studied, one-way ANOVA

Table 5. Mean and range values for yield and its contributing traits ${ }^{\mathrm{z})}$ of each cluster.

\begin{tabular}{ccccccccccc}
\hline \hline Cluster & $\begin{array}{c}\text { No. of } \\
\text { genotypes }\end{array}$ & Parameter & Yld (g) & SI (g) & Ht & Flr & PL & PW & Chl & LA \\
\hline \multirow{2}{*}{ I } & 42 & Mean & 24.63 & 3.14 & 107.25 & 50.81 & 18.43 & 3.57 & 52.44 & 0.02 \\
& & Range & $7.20-51.60$ & $1.75-4.40$ & $37.98-144.55$ & $37.00-66.00$ & $9.00-27.50$ & $2.00-6.50$ & $37.05-63.20$ & $0.009-0.04$ \\
II & \multirow{2}{*}{24} & Mean & 26.01 & 3.12 & 236.02 & 58.46 & 20.03 & 4.80 & 53.81 & 0.02 \\
& & Range & $7.55-54.30$ & $1.90-3.70$ & $214.38-263.38$ & $46.00-69.50$ & $9.50-32.00$ & $2.00-14.50$ & $45.75-60.90$ & $0.01-0.03$ \\
III & \multirow{2}{*}{105} & Mean & 33.67 & 3.35 & 179.81 & 57.15 & 19.86 & 4.92 & 52.56 & 0.02 \\
& & Range & $6.70-74.45$ & $1.75-7.05$ & $140.88-218.05$ & $35.00-73.50$ & $9.00-33.50$ & $2.00-8.50$ & 38.7560 .45 & $0.01-0.04$ \\
IV & \multirow{2}{*}{06} & Mean & 73.07 & 3.73 & 199.06 & 58.25 & 21.13 & 5.88 & 52.61 & 0.03 \\
& & Range & $62.15-95.10$ & $3.35-4.45$ & $181.30-208.25$ & $55.50-64.00$ & $16.00-23.50$ & $4.50-7.00$ & $41.95-61.25$ & $0.02-0.05$ \\
\hline
\end{tabular}

${ }^{\mathrm{z})}$ Yld: Grain yield/plant (g), SW: Seed weight (g), Ht: Plant height (cm), Flr: Days to flower, PL: Panicle length (cm), PW: Panicle width $(\mathrm{cm}), \mathrm{Chl}$ : Chlorophyll content, LA: Leaf area. 
showed significant differences between agro-morphological traits and high estimates of Shannon-Weaver diversity indices indicating that sorghum landraces in North Shewa and South Welo were diverse due to the ecological heterogeneity and climatic variations (Adugna et al. 2002). Results from the present study have revealed that the yield improvement is a complex phenomenon and several traits are influencing the differential yield levels across germplasm lines. A promising variety, ICSV-13001 and a landrace, IC436598 have shown high grain yield and was mainly contributed by panicle length and width.

With respect to genetic variability parameters, grain yield recorded high GCV and PCV values. Lowest GCV and PCV values were recorded for leaf area and chlorophyll content. The PCV values were found higher than GCV for all the traits studied; owing to the fact that environment had little effect on the expression of these traits. These findings were in accordance with the earlier reports (Basu 1981; Abu-Gasim and Kambal 1985; Bello et al. 2007). High heritability values were observed for the traits under study (0.75-0.99) with panicle length, plant height and chlorophyll content registering maximum heritability values. Such a trend for yield traits is highly useful in plant breeding as they enable selection to be based on phenotypic performances (Siddique et al. 2006). In the previous studies also polygenic traits have shown high heritability besides useful correlations among the yield and developmental traits (Seetharam and Ganeshmurthy 2013). High heritability coupled with genetic advance indicates lesser influence of environment and potential of effective plant selections in the progeny lines (Baghalian et al. 2010).

Correlations among morphological and yield traits give valuable information for selections to be effected in the breeding programs. In the present study, days to flower and yield contributing traits (seed weight, panicle width) are significantly correlated with grain yield. In addition, increase in the seed weight was positively correlated with panicle width but negatively related to panicle length. Similarly, in a study involving 13 sorghum cultivars in post rainy season, plant height had negative and highly significant correlation with panicle length, grain weight/panicle and grain yield/ha. On the other hand, panicle length had positive and highly significant correlation with number of grains/panicle, grain weight/panicle and grain yield. Negative association of plant height with grain yield indicated that hybrid with medium tall stature were more suitable in zero till rice fallow situation (Mishra et al. 2011). Among the 200 Ethiopian landraces studied, positive correlation among leaf traits and between leaf traits and yield components were observed. Selection that focuses on key yield components such as larger leaf area, and on enhancing the grain filling rate by reducing excessive grain fill duration may contribute to yield improvement (Tesso et al. 2011). Among the eight sorghum varieties grown in Sudan, grain yield per hectare showed high significant positive correlation with number of grain per panicle and number of panicles per unit area. The variance components for the two environments showed that most of the characters had higher phenotypic and genotypic variance than the environmental variance (Naim et al. 2012).

Classifying genotypes in to morphologically and genetically similar groups is useful in identifying potential parents for recombination breeding (Souza and Sorrels 1991). In the present study, all the genotypes were grouped into four clusters. In line with the present study, cluster analysis based on ordinal variables grouped 34 Ethiopian landraces into five clusters. The differential distribution of landraces revealed the adaptive significance of panicle compactness and shape that reflected the patterns of distribution of different races in north Shewa and south Welo (Adugna et al. 2002). Similarly, analysis of 415 sorghum accessions for 15 traits in Etria region showed a greater proportion of accessions of similar adaptation zones (Ayana and Bekele 1999). Then, accessions from regions of origin with similar agro-climatic conditions were grouped together. The clusters contributing maximum to the divergence were given greater emphasis for further selection and also choosing them as parents in recombination breeding.

Results from the present study have revealed that the yield improvement is a complex phenomenon and several traits are influencing the differential yield levels across germplasm lines. Thus there is need to systematically analyze and interpret the complex association among the 
traits and their utilization for enhancing the yield potential of the crop (Tesso et al. 2011).

\section{ACKNOWLEDGEMENTS}

The authors are thankful to Head, Nuclear Agriculture and Biotechnology Division, and Experimental and Gamma Field Facility Section, Bhabha Atomic Research Centre, Mumbai, India for their support. We also thank NBPGR and ICRISAT, Hyderabad for providing sorghum germplasm lines.

\section{REFERENCES}

Abu-Gasim EH, Kambal AE. 1985. Variability and interrelationship among characters in indigenous grain sorghum of the Sudan. Crop Sci. 11: 308-309.

Adugna A, Bekele E, Asfaw Z, Teshome A. 2002. Patterns of morphological variation of sorghum (Sorghum bicolor (L.) Moench) landraces in qualitative characters in North Shewa and South Welo, Ethiopia. Hereditas 137: 161-172.

Allard RW. 1960. Principal of Plant Breeding. John Wiley and Sons, Inc., New York, pp. 84-85.

Araus JL, Slafer GA, Royo C, Serret MD. 2008. Breeding for yield potential and stress adaptation in cereals. Critical Rev Plant Sci. 27: 377-412.

Ayana A, Bekele E. 1999. Multivariate Analysis of Sorghum (Sorghum bicolor (L.) Moench) germplasm from Ethiopia and Eritrea. Genet. Resour. Crop Evol. 46: 273-284.

Baghalian K, Shabani M, Jamshidi AH. 2010. Genetic variation and heritability of agro-morphological and phytochemical traits in Iranian saffron (Crocus sativa L.) populations. Ind. Crops Prod. 31: 401-410.

Basu AK, 1981. Variability and heritability estimate from Inter-season Sorghum Cross. Indian J. Agric Sci. 41: 116-117.

Bello D, Kadams AM, Simon SY, Mashi DS. 2007. Studies on genetic variability in cultivated sorghum (Sorghum bicolor L. Moench) cultivars of Adamawa State Nigeria. American-Eurasian J. Agric. Environmental Sci. 2: $297-$ 302.
Beuselinck PR, Steiner JJ. 1992. A proposed framework for identifying, quantifying, and utilising plant germplasm resources. Field Crops Res. 29: 261-272.

Burow G, Burke JJ, Xin Z, Franks CD. 2011. Genetic dissection of early-season cold tolerance in sorghum (Sorghum bicolor (L) Moench). Mol. Breed. 28: 391-402.

Burton GW. 1952. Quantitative inheritance in Grasses. In: Proceedings of the Sixth International Grassland Congress, pp. 227-283.

Chapman SC, Cooper M, Hammer GL, Butler DG. 2000. Genotype by environment interactions affecting grain sorghum. II. Frequencies of different seasonal patterns of drought stress are related to location effects on hybrids yields. Australian J. Agric. Res. 51: 209-221.

Charyulu DK, Bantilan MCS, Rajalaxmi A. 2013. Development and Diffusion of Sorghum Improved Cultivars in India: Impact on Growth and Variability in Yield. In: 57th AARES Annual Conference, 5- $8^{\text {th }}$ February, Sydney, New South Wales.

Doggett H. 1988 Sorghum. Wiley, New York.

Elangovan M, Ganesamurthy K, Rajaram S, Sankarapandian K, Babu PK. 2012. Collection and conservation of Sorghum landraces from Tamil Nadu. Electronic J. Plant Breed. 3: 753-762.

FAO. 2014. FAOSTAT. http://faostat3.fao.org.

Franco J, Crossa J, Ribaut J, Bertran J, Warburton M, Khairallah M. 2001. A method for combining molecular markers and phenotypic attributes for classifying plant genotypes. Theor. Appl. Genet. 103: 944-952.

Mamo S, Ayana A, Tesso T. 2007. RAPD variation among long maturing sorghum (Sorghum bicolor (L.) Moench] landraces from Ethiopia. Acta Agronomica Hungary 55: 375-382.

Mishra JS, Subbarayudu B, Chapke RR, Seetharam N. 2011. Evaluation of sorghum (Sorghum bicolor) cultivars in rice (Oryza sativa) fallows under zero tillage. Indian J. Agric. Sci. 81: 277-279.

Naim AME, Ibrahim MI, Rahman MEA, Ibrahim EA. 2012. Evaluation of some local Sorghum (Sorghum bicolor L. Moench) genotypes in rain-fed. Int. J. Plant Res. 2: 15-20.

Narkhede BN, Shinde MS, Patil SP. 1997. Stability performance of sorghum varieties for grain and fodder Yields. J. Maharashtra Agric. Univ. 22: 179-81.

Patil SP, Manjare MR, Kamdi SR, Dethe AM, Ingle MB. 2007. Stability analysis in sorghum (Sorghum bicolor 
(L.). International Journal of Plant Sciences 2: 70-75.

Peeters JP, Martinelli JA. 1989. Hierarchical cluster analysis as a tool to manage variation in germplasm collections. Theor. Appl. Genet. 78: 42-48.

Prabhakar, Elangoan M, Raut M S. 2010. Stability of new varieties for yield components in rabi sorghum (Sorghum bicolor). Indian J. Agric. Sci. 80: 106-109.

Prasada Rao KE, Mengesha MH, Reddy VG, 1989. International use of a sorghum germplasm collection, $\mathrm{p}$. 49-67. In: AHD. Brown, DR. Marshall, OH. Frankel, JT. Williams (eds.). The Use of Plant Genetic Resources, Cambridge University Press, Cambridge,

Reddy BVS, Reddy PS, Sadananda AR, Dinakaran E, Kumar AA, Deshpande SP, et al. 2012. Post-rainy season sorghum: constraints and breeding approaches. J. SAT Agric. Res. 10: 1-12.

SAS. 2010. SAS Statistical Analysis Software for Windows 9.1.3 Cary, NC USA

Seetharam K, Ganesamurthy K. 2013. Characterization of sorghum genotypes for yield and other agronomic traits through genetic variability and diversity analysis.
Electronic J. Plant Breed. 4: 1073-1079.

Souza E, Sorrells ME. 1991. Relationships among 70 American oat germplasm. I. Cluster analysis using quantitative characters. Crop Sci. 31: 599-605.

Siddique M, Malik MFA, Shahid IA. 2006. Genetic divergence, association and performance evaluation of different genotypes of Mungbean (Vigna radiata). Int. J. Agric. Biol. 8: 793-795.

Teshome A, Baum BR, Farig L, Torrance JK, Arnason TJ, Lambert JD. 1997. Sorghum (Sorghum bicolor (L.) Moench) landrace variation and classification in north Shewa and south Welo, Ethiopia. Euphytica. 97: 255-263.

Tesso TA, Tirfessa, Mohammed H. 2011. Association between morphological traits and yield components in the durra sorghums of Ethiopia. Hereditas. 148: 98-109.

Upadhyaya HD, Pundir RPS, Dwivedi SL, Gowda CLL, Reddy VG, Singh S. 2009. Developing a mini core collection of sorghum for diversified utilization of germplasm. Crop Sci. 49: 1769-1780. 